\title{
ANALISIS PENGARUH PROFITABILITAS TERHADAP NILAI PERUSAHAAN DENGAN TAX AVOIDANCE SEBAGAI VARIABEL INTERVENING
}

\author{
Vincensia Arinda \\ Sugi Suhartono* \\ Program Studi Akuntansi, Institut Bisnis dan Informatika Kwik Kian Gie, \\ Jl. Yos Sudarso Kav. 87, Jakarta 14350
}

\begin{abstract}
Accounting information in the form of financial statements is expected to describe the actual condition of the company. Information such as profitability, tax avoidance, company value is one of the many information used in measuring company performance. The grand theories of this research are agency theory and signal theory. The population in this research are 9 manufacturing companies listed in Indonesia Stock Exchange 2011-2015, into a total of 45 samples of the company. Data analysis techniques used are pooling test, classical assumption test, descriptive statistical test, F-test, $t$-test, and coefficient determination of $R$ square. And data obtained from $w w w . i d x . c o . i d$ and $w w w$.finance.yahoo.com. This research proven that there is enough evidence that profitability affects to tax avoidance, there is not enough evidence that profitability affects relevance to company value, there is sufficient evidence that tax avoidance affects to company value, and there is enough evidence that tax avoidance is a mediation between profitability and company value.
\end{abstract}

Key words: Profitability, Tax Avoidance, Company Value

\begin{abstract}
Abstrak
Informasi akuntansi berupa laporan keuangan diharapkan mampu menggambarkan kondisi perusahaan yang sebenarnya. Informasi seperti profitabilitas, tax avoidance, nilai perusahaan merupakan salah satu dari banyak informasi yang digunakan dalam mengukur kinerja perusahaan. Teori yang mendasari penelitian ini antara lain teori keagenan dan teori sinyal. Populasi dari penelitian ini adalah 9 perusahaan manufaktur terdaftar dalam Bursa Efek Indonesia tahun 20112015, menjadi totalnya terdapat 45 sampel perusahaan. Teknik analisis data yang digunakan adalah uji pooling, uji asumsi klasik, uji statistik deskriptif, uji $F$, uji t, dan uji koefisien determinasi. Dan data didapatkan dari www.idx.co.id dan www.finance.yahoo.com. Hasil penelitian ini menunjukan bahwa terdapat cukup bukti bahwa profitabilitas berpengaruh terhadap tax avoidance, tidak terdapat cukup bukti bahwa profitabilitas berpengaruh terhadap nilai perusahaan, terdapat cukup bukti bahwa tax avoidanceberpengaruh terhadap nilai perusahaan, dan terdapat cukup bukti bahwa tax avoidance merupakan mediasi antara profitabilitas dan nilai perusahaan.
\end{abstract}

Kata kunci: Profitabilitas, Tax Avoidance, Nilai Perusahaan

\footnotetext{
* Alamat kini:Institut Bisnis dan Informatika Kwik Kian Gie, Jln Yos Sudarso Kav. 87 Sunter, Jakarta 14350 Penulis untuk Korespondensi: Telp. (021) 65307062 Ext. 222. E-mail: sugi.suhartono@kwikkiangie.ac.id
} 


\section{Pendahuluan}

engertian pajak menurut Pasal 1 UU No. 28 Tahun 2007, pajak adalah kontribusi wajib kepada negara yang terutang oleh orang pribadi atau badan yang bersifat memaksa berdasarkan undang-undang dengan tidak mendapatkan imbalan secara langsung dan digunakan untuk keperluan negara bagi sebesar-besarnya kemakmuran rakyat. Pajak merupakan sumber utama penerimaan negara yang digunakan untuk membiayai pengeluaran negara. Bila pemungutan pajak ditingkatkan, maka secara otomatis penerimaan negara akan bertambah besar, dengan demikian pemerintah akan lebih leluasa dalam membiayai kegiatan pemerintah dan pembangunan. Semakin besar penerimaan pajak, semakin besar pula dana yang dapat dipergunakan untuk pembiayaan pengeluaran negara. Perpajakan di Indonesia dibangun diatas prinsip kegotongroyongan. Dalam laporan keuangan pemerintah pusat tahun 2015 realisasi pendapatan perpajakan mencapai Rp1.240.418,9 miliar atau naik 8,16 persen dibanding realisasi tahun 2014 sebesar Rp1.146.865,8 miliar. Pendapatan perpajakan tahun 2015 berasal dari penerimaan pajak dalam negeri sebesar Rp1.205.478,9 miliar dan penerimaan pajak perdagangan internasional sebesar Rp34.940,0 miliar. Peningkatan penerimaan pajak tidak diikuti dengan kenaikan tax ratio. Tax ratio merupakan perbandingan antara jumlah penerimaan perpajakan dibandingkan dengan Produk Domestik Bruto (PDB) suatu negara. Produk Domestik Bruto (PDB) 2015 atas dasar harga berlaku menggunakan tahun dasar 2010 mencapai Rp11.540,8 triliun, sehingga rasio perpajakan terhadap produk domestik bruto (PDB) mencapai 10,75 persen pada 2015. Tax ratio Indonesia tahun 2015 lebih rendah dibandingkan tahun 2014 yang mencapai 11,9 persen meskipun penerimaan pajak 2015 mengalami kenaikan.

Sejak 1984 Indonesia menganut selfassessment system yang memberi kepercayaan kepada wajib pajak untuk menghitung, memperhitungkan, membayar, dan melaporkan sendiri pajak terutang. Peran otoritas pajak adalah melakukan fungsi pembinaan, penelitian, pengawasan, dan penerapan sanksi administrasi. Keberhasilan self-assessment system sangat bergantung pada kesadaran dan peran serta masyarakat (voluntary compliance), maka edukasi dan komunikasi perlu terus-menerus dilakukan. Akan tetapi pemungutan pajak bukanlah tanpa masalah, terdapat perbedaan kepentingan antara pemerintah sebagai pemungut pajak dan perusahaan sebagai wajib pajak. Manfaat pajak bagi Negara adalah untuk membiayai penyelenggaraan pemerintahan, tetapi bagi perusahaan pajak adalah beban. Sehingga dalam suatu perusahaan beban perpajakan harus dikelola dengan baik agar laba perusahaan yang lebih besar. Menurut Frank, Lynch dan Rego (2009), agresivitas pajak perusahaan adalah suatu tindakan merekayasa pendapatan kena pajak yang dirancang melalui tindakan perancanaan pajak (tax planning) baik menggunakan cara yang tergolong secara legal (tax avoidance) atau ilegal (tax evasion). Tax avoidance menurut Zain (2008) adalah usaha untuk mengurangi, menghindari, serta meringankan beban dengan berbagai cara yang dimungkinkan oleh perundang-undangan perpajakan dengan memperhatikan ada atau tidaknya suatu akibat pajak yang ditimbulkannya.

Praktek tax avoidance biasanya memanfaatkan kelemahan-kelemahan hukum pajak dan tidak melanggar hukum perpajakan. Selain memberikan keuntungan bagi pihak perusahaan, penghindaran pajak juga dapat memberikan efek negatif bagi perusahaan. Hal ini disebabkan karena tax avoidance dapat mencerminkan adanya kepentingan pribadi manajer dengan cara melakukan manipulasi laba yang mengakibatkan adanya informasi yang tidak benar bagi investor. Profitabilitas merupakan gambaran kinerja keuangan perusahaan dalam menghasilkan laba dari pengelolaan aktiva yang dikenal dengan Return on Asset (ROA). ROA yang positif menunjukkan bahwa dari total aktiva yang 
dipergunakan untuk beroperasi perusahaan mampu memberikan laba bagi perusahaan. ROA dinyatakan dalam prosentase, semakin tinggi nilai ROA, maka akan semakin baik kinerja perusahaan tersebut. Nilai ROA yang tinggi berarti perusahaan mampu menghasilkan laba yang tinggi, yang berarti profitabilitasnya juga tinggi. Perusahaan yang profitabilitasnya tinggi berarti manajemen perpajakan yang dilakukan oleh perusahaan efektif, salah satu cara manajemen pajak yaitu dengan cara tax avoidance yang dilakukan oleh perusahaan dalam mengurangi pembayaran pajak. Dengan demikian para investor dapat memberikan penilaian bagi perusahaan yang dapat dilihat dari profitabilitas dan tax avoidance yang dilakukan perusahaan, jika perusahaan tersebut mendapat penilaian yang baik dari para investor maka investor akan menanamkan saham mereka pada perusahaan. Berdasarkan uraian di atas, dapat dirumuskan hHipotesis sebagai berikut :

H1: Profitabilitas berpengaruh signifikan negatif terhadap tax avoidance.

$\mathrm{H} 2$ : Profitabilitas berpengaruh signifikan positif terhadap nilai perusahaan.

H3: Tax avoidance berpengaruh signifikan prositif terhadap nilai perusahaan.

H4: Tax avoidance memediasi profitabilitas dengan nilai perusahaan.

\section{Metode Penelitian}

Obyek penelitian dalam penelitian ini adalah Obyek penelitian dalam penelitian ini adalah perusahaan-perusahaan manufaktur yang terdaftar di Bursa Efek Indonesia dan memiliki laporan keuangan secara lengkap, audited, menyajikan dalam mata uang rupiah, tidak terjadi rugi, tidak delisting, memiliki CETR dibawah $25 \%$ selama 5 tahun berturutturut dari tahun 2011 sampai dengan tahun 2015. Data berasal dari www.idx.co.id dan www.finance.yahoo.com untuk memperoleh harga per lembar saham tahun 2011 dan tahun 2012. Jumlah sampel yang dijadikan obyek penelitian adalah sebanyak 9 perusahaan selama lima tahun.

\section{Variabel Dependen}

\section{Nilai Perusahaan}

Variabel dependen yang digunakan dalam penelitian ini adalah nilai perusahaan, menurut Brigham dan Erdhadt (2005: 518) nilai perusahaan merupakan nilai sekarang (present value) dari free cash flow di masa mendatang pada tingkat diskonto sesuai ratarata tertimbang biaya modal. Nilai perusahaan diwakili oleh Price Earning Ratio (PER), PER dapat dihitung dengan cara:

$$
\text { PEK }=\frac{\text { Harga per lembar saham }}{\text { Laba per lembar saham }}
$$

\section{Variabel Independen}

\section{Profotabilitas}

Dalam penelitian ini variabel profitabilitasdiwakili olehReturn on Assets (ROA).Menurut Menurut R. Agus Sartono (2010:122) profitabilitas adalah kemampuan perusahaan memperoleh laba dalam hubungannya dengan penjualan, total aktiva maupun modal sendiri.Rasio ini menurut Sutrisno (2012:222) dapat dihitung dengan formula:

ROA $=\frac{\text { Earning Before Interest and } T a x}{\text { Total Assets }} \times 100 \%$

\section{Variabel Intervening}

\section{Tax Avoidance}

Dalam penelitian ini, tax avoidancediwakili oleh Current Effective Tax Rate (CETR). ). Menurut Mardiasmo (2003) dalam Budiman dan Setiyono (2012) pengertian tax avoidance atau penghindaran pajak yang lain adalah suatu usaha meringankan beban pajak dengan tidak melanggar undang-undang yang ada. ), Menurut Hanlon dan Heitzman (2010) CETR dapat dihitung dengan cara: 


\section{$C E T R=\frac{\text { Worldwide current incume tax experwe }}{\text { Worldwide incume pre }- \text { tax accounting incume }}$}

\section{Teknis Analisis data}

Dalam melakukan pengolahan data dan menganalisis data-data yang diperoleh untuk mendapatkan informasi yang diinginkan, peneliti menggunakan alat bantu pengolahan data berupa penggunaan software (perangkat lunak) yaitu Microsoft Excel 2013 dan SPSS versi 20. Dalam penelitian ini penulis menggunakan uji kesamaan koefisien untuk mengetahui apakah pooling data dapat dilakukan. Selain itu, penulis juga menggunakan analisis statistik deskriptif untuk mengetahui gambaran umum dari semua variabel yang diuji dalam penelitian, Penulis juga menggunakan uji asumsi klasik yang terdiri dari uji normalitas, uji multikolinearitas, uji heterokedastisitas, uji autokorelasi serta dilakukan uji $\mathrm{F}$, uji $\mathrm{T}$, dan uji koefisien determinasi dan sobel test untuk mengetahui seberapa besar variabel intervening memediasi variabel dependen dan independen.

\section{Hasil Dan Pembahasan}

Tabel 1

Hasil Uji Kesamaan Koefisien

\begin{tabular}{lr}
\hline Variabel & Sig \\
\hline Profitabilitas &, 996 \\
Tax Avoidance &, 541 \\
Nilai Perusahaan &, 000 \\
D1 &, 889 \\
D2 &, 597 \\
D3 &, 676 \\
D4 &, 367 \\
ROA_D1 &, 905 \\
ROA_D2 &, 913 \\
ROA_D3 &, 503 \\
ROA_D4 &, 934 \\
CETR_D1 &, 963 \\
CETR_D2 &, 690 \\
CETR_D3 &, 613 \\
CETR_D4 &, 406 \\
\hline
\end{tabular}

Berdasarkan hasil pengujian dari tabel di atas, dapat dilihat bahwa seluruh variabel dummy yang berinteraksi dengan variabel bebas memiliki nilai sig. lebih besar dari p-vallue (>
0,05), sehingga dapat disimpulkan bahwa tidak ada perbedaan garis diagonal sepanjang tahun sehingga data dapat dipool. 
Tabel 2

Hasil Statistik Deskriptif

\begin{tabular}{lrrrrrr}
\hline & N & Minimum & Maximum & \multicolumn{1}{c}{ Mean } & Std. Error & \multicolumn{1}{c}{$\begin{array}{c}\text { Std. } \\
\text { Deviation }\end{array}$} \\
\hline Profitabilitas & 45 &, 02548 &, 55513 &, 2032397 &, 02092434 &, 14036474 \\
Tax Avoidance & 45 &, 10973 &, 24925 &, 2175150 &, 00469448 &, 03149156 \\
Nilai Perusahaan & 45 & 3,14938 & 98,93617 & 22,3533044 & 2,54442494 & 17,06852138 \\
\hline
\end{tabular}

Analisis statistik deskriptif dari variabel-variabel yang diuji dalam penelitian ini disajikan dalam tabel2 yang menunjukkan bahwa rata-rata Profitabilitas (ROA) sebesar 0,2032397dengan angka terendah sebesar 0,02548 dan tertinggi 0,55513 sebesar dengan standar deviasi sebesar 0,14036474, rata-rata Tax Avoidance (CETR) adalah
0,2175150 dengan nilai terendah adalah 0,10973dan nilai tertinggi 0,24925 dengan standar deviasi sebesar 0,03149156, rata-rata untuk Nilai Perusahaan (PER) adalah 22,3533044 dengan nilai terendah adalah 3,14938 dan tertinggi 98,93617 dengan standar deviasi sebesar 17,06852138.

Tabel 3

Hasil Uji Asumsi KlasikProfitabilitas Terhadap Tax Avoidance

\begin{tabular}{|c|c|c|c|c|}
\hline \multirow{3}{*}{ Variabel } & \multicolumn{4}{|c|}{ Jenis Pengujian } \\
\hline & \multirow{2}{*}{ Normalitas } & \multicolumn{2}{|c|}{ Multikolinieritas } & \multirow{2}{*}{ Autokorelasi } \\
\hline & & Tol & VIF & \\
\hline ROA & $\begin{array}{l}\text { Asymp. Sig (2-tailed })=0,156 \\
>0,05\end{array}$ & 1,000 & 1,000 & $1,5660<2,077<2,434$ \\
\hline
\end{tabular}

Dari hasil pengujian yang dapat dilihat pada tabel 3 untuk menguji apakah terjadi normalitas dengan menggunakan uji onesample Kolmogorov Smirnov sehingga dilihat bahwa nilai Asymp. Sig (2-tailed) adalah sebesar $0,156>0,05$ yang menunjukkan bahwa nilai residual telah terdistribusi secara normal. . Untuk menguji apakah terjadi multikolinieritas dengan menggunakan besaran tolerance (a) dan variance inflation factor (VIF) jika menggunakan alpha/tolerance $=10 \%$ atau 0,10 maka VIF $=$ 10. Dari hasil output VIF hitung dari kedua variabel $=1,000<\mathrm{VIF}=10$ dan tolerance variabel bebas $1,000>0,10$. Dapat disimpulkan bahwa antara variabel bebas tidak terjadi multikolinieritas. Untuk menguji apakah terjadi autokorelasi dengan menggunakan nilai dari Durbin Watson sehingga nilai $\mathrm{dw}$ hitung didapat sebesar 2,077 lebih besar dari du=1,5660 dan lebih kecil dari 4-du= 2,434. Dapat disimpulkan bahwa tidak terjadi autokorelasi. Untuk menguji apakah terjadiheterokedastisitas dari output di atas dapat diketahui bahwa titik-titik tidak membentuk pola yang jelas, dan titiktitik menyebar di atas dan di bawah angka 0 pada sumbu Y. Jadi dapat disimpulkan bahwa tidak terjadi masalah heteroskedastisitas dalam model regresi. 
Tabel 4

Hasil Uji Signifikansi Simultan Profitabilitas Terhadap Tax Avoidance

\begin{tabular}{lc}
\hline Model & Sig. \\
\hline Regression &, $000^{\mathrm{b}}$ \\
Residual & \\
Total & \\
\hline
\end{tabular}

Dari hasil pengujian untuk signifikansi simultan (uji F) yang dapat dilihat pada tabel 4 dapat dilihat bahwa nilai sig. sebesar 0,000 dimana lebih kecil dari 0,05 . Hal itu menunjukan bahwa variabel profitabilitas berpengaruh terhadap variabel dependennya yaitu tax avoidance.

Tabel 5

Hasil Uji Signifikansi Simultan

Profitabilitas dan Tax Avoidance Terhadap Nilai Perusahaan

\begin{tabular}{lc} 
Model & Sig. \\
\hline Regression &, $014^{\mathrm{b}}$ \\
Residual & \\
Total & \\
\hline
\end{tabular}

Dari hasil pengujian untuk signifikansi simultan (uji F) yang dapat dilihat pada tabel 5 dapat dilihat bahwa nilai sig. sebesar 0,014 dimana lebih kecil dari 0,05. Hal itu menunjukan bahwa variabel profitabilitas dan tax avoidance secara bersama-sama berpengaruh terhadap variabel dependennya yaitu nilai perusahaan.

Tabel 6

Hasil Uji Koefisien Regresi Parsial Profitabilitas Terhadap Tax Avoidance

\begin{tabular}{ccc}
\hline Model & $\begin{array}{c}\text { Unstandardized } \\
\text { Coefficients } \\
\text { B }\end{array}$ & Sig. \\
\hline (Constant) & 0,193 & 0,000 \\
Profitabilitas & 0,123 & 0,000 \\
\hline
\end{tabular}

Dari hasil pengujian untuk koefisien regresi (uji t) yang dapat dilihat pada tabel 6 dapat dilihat bahwa profitabilitas yang diwakili oleh ROA memiliki tingkat signifikansi sebesar 0,000 dimana lebih kecil dari 0,05.Hal itu menunjukan tidak sesuai dengan hipotesis dimana profitabilitas berpengaruh signifikan terhadap tax avoidance. Nilai e1 didapat dari:

$E 1=\sqrt{(1-0,3}$ 
Berdasarkan hasil perhitungan maka dapat dirumuskan persamaan regresi sebagai berikut :

T'ax Avoidance $=0,193+0,123 X+0,83666$

\section{Tabel 7 \\ Hasil Uji Koefisien Regresi Parsial Profitabilitas dan Tax Avoidance Terhadap Nilai Perusahaan}

\begin{tabular}{lrr}
\hline & \multicolumn{2}{c}{$\begin{array}{c}\text { Unstandardized } \\
\text { Coefficients }\end{array}$} \\
\cline { 2 - 3 } \multicolumn{1}{c}{ Model } & \multicolumn{1}{c}{ Sig. } \\
\hline (Constant) & $-24,308$ &, 181 \\
Profitabilitas & 9,755 &, 633 \\
Tax Avoidance & 205,406 &, 028 \\
\hline
\end{tabular}

Dari hasil pengujian untuk koefisien regresi (uji t) yang dapat dilihat pada tabel 7 dapat dilihat bahwa profitabilitas yang diwakili oleh ROA memiliki tingkat signifikansi sebesar 0,633 dan dimana lebih besar dari 0,05 . Hal ini tidak sesuai dengan hipotesis dimana profitabilitas tidak berpengaruh signifikan terhadap nilai perusahaan. Tax Avoidance yang diwakili oleh CETR memiliki tingkat signifikansi sebesar 0,028 dimana lebih kecil dari 0,05 . Hal ini menunjukan terima hipotesis dimana tax avoidance berpengaruh signifikan terhadap nilai perusahaan. Nilai e2 didapat dari:

Berdasarkan hasil perhitungan maka dapat dirumuskan persamaan regresi sebagai berikut:

Nilai Perusahaan $=-24,308+9,755 X+205,406 Z+0,90388$

Tabel 8

Hasil Uji Sobel Test

Standar eror dari koefisienindirect effect

12,877422

\begin{tabular}{lr}
\hline Pengaruh tidak langsung dari tax avoidance $(p 2 \times p 3)$ & 25,26494 \\
\hline $\begin{array}{l}\text { Total pengaruh profitabilitas terhadap nilai perusahaan lewat tax } \\
\text { avoidance }(p 1+(p 2 \times p 3))\end{array}$ & 35,01994 \\
\hline t hitung & \\
$\qquad\left(\frac{p 2 p 3}{S p 2 p 3}\right)$ & 9,643301181 \\
\hline $\mathrm{t}$ table & 1,68107 \\
\hline
\end{tabular}


Keterangan:

\begin{tabular}{lrr}
\hline Unstandardized coefficient beta of profitabilitas to tax avoidance & 0,123 & $\mathrm{p} 2$ \\
\hline Std error of profitabilitas to tax avoidance & 0,029 & $\mathrm{Sp} 2$ \\
\hline Unstandardized coefficient beta of tax avoidance to nilai perusahaan & 205,406 & $\mathrm{p} 3$ \\
\hline Std error of tax avoidance to nilai perusahaan & 90,343 & $\mathrm{Sp} 3$ \\
\hline Unstandardized coefficient beta of profitabilitas to nilai perusahaan & 9,755 & $\mathrm{p} 1$ \\
\hline
\end{tabular}

Hasil perhitungan diatas didapat nilai $t$ hitung lebih besar dari nilai t tabel dengan tingkat signifikan 0,05 yaitu sebesar 1,68107 maka dapat disimpulkan bahwa koefisien mediasi 25,26494 signifikan yang berarti ada pengaruh mediasi, dengan kata lain tax avoidance terbukti sebagai variabel intervening antara profitabilitas dengan nilai perusahaan.

Tabel 9

Hasil Uji Koefisien Determinasi Profitabilitas Terhadap Tax Avoidance

\begin{tabular}{lr}
\hline Model & $\begin{array}{c}\text { Adjusted } \mathrm{R} \\
\text { Square }\end{array}$ \\
\hline 1 &, 300
\end{tabular}

Dari hasil uji koefisien determinasi pada tabel 9 diatas besarnya nilai adjusted $\mathrm{R}^{2}$ adalah 0,300 , nilai tersebut dapat diartikan bahwa $30 \%$ variasi Tax Avoidance dapat dijelaskan oleh variabel Profitabilitas. Sedangkan sisanya $70 \%$ dijelaskan oleh variabel lainnya di luar penelitian.

Tabel 10

Hasil Uji Koefisien Determinasi Profitabilitas dan Tax Avoidance Terhadap Nilai Perusahaan

\begin{tabular}{lr}
\hline Model & $\begin{array}{c}\text { Adjusted } \mathrm{R} \\
\text { Square }\end{array}$ \\
\hline 1 &, 183 \\
\hline
\end{tabular}

Dari hasil uji koefisien determinasi pada tabel 10 diatas besarnya nilai adjusted $\mathrm{R}^{2}$ adalah 0,183 , nilai tersebut dapat diartikan bahwa $18,3 \%$ nilai perusahaan dapat dijelaskan oleh variabel profitabilitas dan tax avoidance. Sedangkan sisanya $81,7 \%$ dijelaskan oleh variabel lainnya di luar penelitian.

\section{Pembahasan}

Profitabilitas tidak berpengaruh terhadap tax avoidance

Jurnal Akuntansi
Berdasarkan hasil tabel 7 dapat dilihat bahwa tingkat signifikan profitabilitas yang diwakili oleh ROA terhadap tax avoidance sebesar $0,000<0,05$ dan beta sebesar 0,123, dapat disimpulkan bahwa profitabilitas berpengaruh postif signifikan terhadap tax avoidance. Hal tersebut sesuai dengan penelitian yang dilakukan oleh Rinaldi dan Charoline Cheisviyanny (2015) yang menyatakan bahwa profitabilitas berpengaruh signifikan positif terhadap tax avoidance pada perusahaan manufaktur di BEI tahun 2010 2013. Setelah dilakukan penelitian ini maka 
dapat dilihat bahwa semakin tinggi profitablitas perusahaan maka semakin tinggi pula tax avoidance yang dilakukan, karena perusahaan dengan nilai profitabilitas yang tinggi dapat berarti perusahaan tersebut memiliki kemampuan yang tinggi dalam memperoleh laba dalam hubungannya dengan total aktiva. Perusahaan dengan tingkat kemampuan memperoleh laba yang tinggi akan melakukan tax avoidance yang tinggi pula karena perusahaan akan tetap menjaga agar laba yang dihasilkan besar sehingga perusahaan akan melalukan berbagai cara untuk meningkatkan laba perusahaan, salah satunya dengan tax avoidance.Penelitian ini bertentangan dengan penelitian Wirna Yola Agusti (2014) yang menyatakan profitabilitas yang diproksikan dengan return on asset (ROA) berpengaruh signifikan negatif terhadap tax avoidance yang dilakukan perusahaan.

\section{Profitabilitas memiliki berpengaruh terhadap nilai perusahaan}

Berdasarkan hasil tabel 7 dapat dilihat bahwa tingkat signifikan profitabilitas yang diwakili oleh ROA terhadap tax avoidance sebesar 0,633>0,05 dan beta sebesar 9,755, dapat disimpulkan bahwa profitabilitas berpengaruh postif tidak signifikan terhadap nilai perusahaan. Hal tersebut sesuai dengan penelitian yang dilakukan oleh Christiana Warouw, Sintje Nangoy, dan Ivonne S. Saerang (2015) yang menyatakan bahwa profitabilitas tidak memiliki pengaruh dengan nilai perusahaan pada Perusahaan Farmasi di Bursa Efek Indonesia periode 2010-2013. Investor tidak melihat profitabilitas yang diukur dengan ROA sebagai salah satu pertimbangan untuk membeli saham suatu perusahaan, karena jika suatu perusahaan baik dalam memelihara asset yang dipunya tidak berpengaruh dengan keputusan investor dalam membeli saham, profitabilitas dapat diukur dengan pengukuran lain yang lebih dapat membantu investor dalam melihat seberapa besar perusahaan tersebut dapat menguntungkan bagi para investor. Penelitian ini bertentangan dengan penelitian Ria Nofrita (2013) yang menyatakan bahwa berdasarkan uji secara parsial (uji t) antara profitabilitas terhadap nilai perusahaan, diperoleh hasil bahwa profitabilitas berpengaruh signifikan positif terhadap nilai perusahaan.

\section{Tax avoidance berpengaruh terhadap nilai perusahaan}

Berdasarkan hasil tabel 8 dapat dilihat bahwa tingkat signifikan tax avoidance yang diwakili oleh PER terhadap nilai perusahaan sebesar $0,028<0,05$ dan beta sebesar 205,406, dapat disimpulkan bahwa tax avoidance berpengaruh postif signifikan terhadap nilai perusahaan,sesuai dengan hipotesis. Penelitian ini bertentangan dengan penelitian yang dilakukan oleh Jonathan dan Vivi Adeyani Tandean (2016) yang menyatakan bahwa tax avoidance tidak memiliki cukup bukti berpengaruh positif terhadap nilai perusahaan.

\section{Tax avoidance memediasi profitabilitas dengan nilai perusahaan}

Berdasarkan hasil uji sobel test nilai t hitung lebih besar dari nilai t tabel dengan tingkat signifikan 0,05 yaitu sebesar 1,68107 maka dapat disimpulkan bahwa koefisien mediasi 25,26494 signifikan yang berarti ada pengaruh mediasi, dengan kata lain tax avoidance terbukti sebagai variabel intervening antara profitabilitas dengan nilai perusahaan. Dengan kata lain profitabilitas tidak dapat secara langsung mempengaruhi nilai perusahaan, harus melalui tax avoidance sebagai mediasi antara profitabilitas dengan nilai perusahaan. Perusahaan yang profitabilitas tinggi cenderung melakukan tax avoidance karena perusahaan tersebut ingin mendapatkan laba yang besar pula pada tahun tersebut. Dan tax avoidance mempengaruhi nilai perusahaan dimana jika tax avoidance meningkat nilai perusahaan juga akan meningkat karena investor melihat bahwa perusahaan tersebut memiliki manajemen keuangan yang baik. Penelitian ini 
bertentangan dengan penelitian Wirna Yola Agusti (2014) yang menyatakan profitabilitas yang diproksikan dengan return on asset (ROA) berpengaruh signifikan negatif terhadap tax avoidance yang dilakukan perusahaan dan bertentangan dengan penelitian yang dilakukan oleh Jonathan dan Vivi Adeyani Tandean (2016) yang menyatakan bahwa tax avoidance tidak memiliki cukup bukti berpengaruh positif terhadap nilai perusahaan.

\section{Simpulan Dan Saran}

Berdasarkan hasil analisis dari penelitian yang telah penulis lakukan, maka kesimpulan yang dapat diambil untuk menjawab masalah adalah terdapat cukup bukti bahwa profitabilitas berpengaruh terhadap tax avoidance, tidak terdapat cukup bukti bahwa profitabilitas berpengaruh terhadap nilai perusahaan, terdapat cukup bukti bahwa tax avoidance berpengaruh terhadap nilai perusahaan., terdapat cukup bukti bahwa tax avoidance merupakan mediasi antara profitabilitas dengan nilai perusahaan.

Berdasarkan penelitian yang telah dilakukan oleh penulis, terdapat beberapa saran yang ingin penulis sampaikan adalah disarankan bagi peneliti selanjutnya sebaiknya menambah variabel lainnya guna dapat lebih diketahui faktor-faktor yang mempengaruhi nilai perusahaan.Peneliti selanjutnya bisa menggunakan rasio-rasio yang lainnya seperti untuk profitabilitasbisa menggunakan Gross Profit Margin, Net Profit Margin, ROE (Return on Equity), ROI (Return on Investment), EPS (Earning per Share), Operating Profit Margin, dan Operating Ratio, untuk Tax Avoidance bisa menggunakan GAAP ETR atau Cash ETR, untuk Nilai Perusahaan bisa menggunakan Price Book Value Ratio (PBVR), Market Book Ratio (MBR), Dividend Yield Ratio, dan Dividend Payout Ratio (DPR).Penelitian selanjutnya diharapkan dapat menambah periode penelitian, hal ini disebabkan peneliti hanya menggunakan jumlah sampel selama lima tahun sehingga masih belum untuk menggeneralisasi hasil penelitian.Disarankan untuk para pemegang saham agar dapat mempertimbangkan profitabilitas, tax avoidance dan nilai perusahaan terlebih dahulu sebelum membeli saham suatu perusahaan.

\section{Daftar Pustaka}

Brigham, E.F., Ehrhardt, M.C. 2005. Financial Management Theory And Practice, Eleventh Edition, Ohio: South Western Cengage Learning.

Budiman, Judi dan Setiyono. 2012. Pengaruh Karakter Eksekutif Terhadap Penghindaran Pajak (Tax Avoidance), Simposium Nasional Akuntansi XV

Fahmi, Irham. 2013. Analisis Laporan Keuangan, Bandung: Alfabeta.

Frank, M. M., Lynch, L. J., \& Rego, S. O. 2009. Tax Reporting Aggressiveness and Its Relation to Aggressive Financial Reporting, The Accounting Review, Vol. 84, 467-496.

Ghozali, Imam. 2013. Aplikasi Analisis Multivariate dengan Program SPSS, Edisi Ketujuh, Semarang : Badan Penerbit Universitas Diponegoro

Hanlon, Michelle dan Heitzman, Shane . 2010. A review of tax research, Journal of Accounting and Economics 50 (40) hal 127 - 178.

Jensen, M. and Mecking, W. 1976. Theory of The Firm: Managerial Behaviour,Agency Costs and Ownership Stucture, Journal of 
Financial Economics 3(4) hal 305360

Sartono, Agus. R. 2010. Manajemen Keuangan Teori dan Aplikasi, Edisi Keempat, Yogyakarta: BPFE

Sutrisno. 2012. Manajemen Keuangan Teori Konsep dan Aplikasi, edisi 8, Yogyakarta: Ekonisia

Zain, Mohammad (2008), Manajemen Perpajakan, Edisi 3, Jakarta: Salemba Empat http://www.finance.yahoo.com diakses 25 Mei 2017

http://www.idx.co.id diakses 25 Mei 2017

http://www.kemenkeu.go.id/Berita/menkeutax-ratio-indonesia-di-bawah-standar diakses tanggal 15 Maret 2017

http://www.kemenkeu.go.id/sites/default/files/ LKPP\%202015\%20Audited.pdf diakses tanggal 15 Maret 2017

http://www.pajak.go.id/content/belajar-pajak diakses tanggal 5 April 2017 